\title{
Comparison of classic and 4-phase rhinomanometry methods, is there any difference?*
}

Eugene H.C. Wong and Ron Eccles

Common Cold Centre and Healthcare Clinical Trials, Cardiff School of Biosciences, Cardiff University, United Kingdom
Rhinology 52: 360-365, 2014

DOl:10.4193/Rhino13.187

*Received for publication:

October 24, 2013

Accepted: April 3, 2014

\begin{abstract}
Background: There are various different parameters used to measure nasal airway resistance (NAR) in rhinomanometry, which include the classic method at fixed pressure of $150 \mathrm{~Pa}$ or $75 \mathrm{~Pa}$ and 4-phase rhinomanometry. This study aims to determine if there is any difference between the measurements of NAR obtained by the classic and 4-phase rhinomanometry methods.
\end{abstract}

Methodology: In-vitro study with measurements of NAR using both methods when applied across four artificial nose models.

Results: No statistically significant differences were found between NAR values obtained from both methods. Strong, positive correlations were found between NAR measured with both methods, which were statistically significant. Bland-Altman method also showed good agreement between both methods with narrow limits of agreement.

Conclusion: There is high level of conformity between the values of nasal airway resistance measured using both methods.

Key words: rhinomanometry, classic, 4-phase, difference, parameters

\section{Introduction}

Rhinomanometry is a functional test ${ }^{(1)}$ to objectively measure the physiological ${ }^{(1)}$ nasal patency ${ }^{(2)}$. It involves measurement of nasal airflow and the pressure gradient required to achieve that flow ${ }^{(2)}$, from which nasal airway resistance (NAR) can then be calculated ${ }^{(3)}$. Depending on the technique used, NAR of each separate nasal passage (anterior or modified posterior rhinomanometry) or integrated measurement of both nasal passages simultaneously (posterior rhinomanometry) can be obtained ${ }^{(3)}$.

Several mathematical models with different parameters can be used to calculate NAR in rhinomanometry. In 1984, the International Standardization Committee on Objective Assessment of the Nasal Airway (ISOANA) recommended that nasal resistance should be calculated at a fixed pressure gradient of $150 \mathrm{~Pa}$ (P150) ${ }^{(4)}$. If this pressure level is not reached, the resistance can be measured at a lower pressure level of $75 \mathrm{~Pa}(\mathrm{P} 75)^{(5)}$. Another way of measuring nasal resistance is the Broms method ${ }^{(6)}$ where resistance is calculated at the intersection point between the Pressure-Flow curve and radius 200 (R200). In 2010, Vogt et al. (7) introduced another new method called 4-phase rhinomanometry (4PR) where nasal resistance is calculated by integrating the vertex resistance (VR) and effective resistance (Reff) in the analysis of the 4 different phases of breathing ${ }^{(7)}$.

Each author has described his or her own methods as the better way of measuring nasal resistance for various reasons. For example, Vogt et al. ${ }^{(7)}$ described the 4-phase rhinomanometry as the superior method compared to the classic single-point methods due to better statistical correlation between their measurements and the subjective feeling of obstruction, as well as providing better diagnostic information due to its consideration of the entire nasal breathing. 
Modern computerized rhinomanometers like NR6 Rhinomanometer (GM Instruments, Glasgow, UK) utilise software that allows nasal resistance to be calculated by all the 3 different methods. The Broms method is mainly used where it originated, in Scandinavia, and the 4-phase method is now promoted as being superior to the classic method despite the long history of use of the classic method in clinical trials on medicines and nasal surgery.

There have been a few clinical studies comparing various mathematical models in rhinomanometry ${ }^{(8-10)}$, but there has not been any study comparing the classic and the 4-phase rhinomanometry methods.

The null hypothesis $(\mathrm{H} 0)$ for this study is that there are no statistically significant differences between the nasal resistances obtained from the classic and 4-phase methods.

\section{Materials and methods}

\section{Rhinomanometer}

An NR6-2 Rhinomanometer Clinical/Research model (GM Instruments, Glasgow, UK) was used for all the measurements in this study. It uses NARIS software that allows nasal resistance to be calculated using the classic (at P150 and P75), 4-phase rhinomanometry (at P150 and P75 including the logarithmic transformation of vertex resistance (LVR) and effective resistance (LER)) and Broms (R200) methods. Only the classic and 4-phase methods were compared in this study.

\section{Model noses}

The model noses used in this study were developed in 1997 (11) and have been used since then as calibration devices for rhinomanometers, and are marketed as 'Rhinocal' units (GM instruments, Glasgow, UK). They consist of cylindrical bodies of different fixed resistances (diameters) and attachments for pressure tube, flowhead and airflow as illustrated in Figure 1.

Rhinocal resistance units were used instead of human volunteers to eliminate the variability in human nasal resistance that is associated with many factors such as the nasal cycle. Four different Rhinocal resistance units were used in this study with

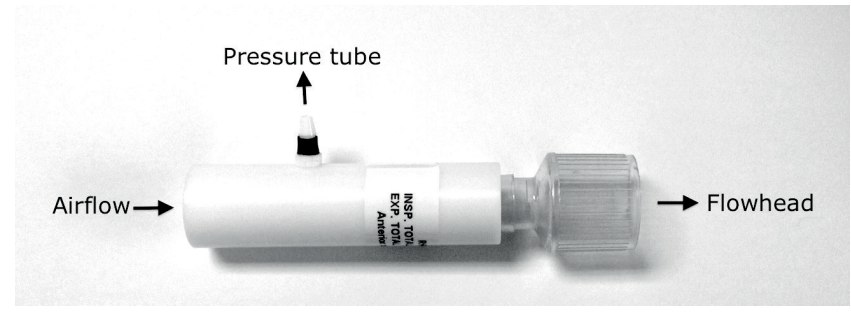

Figure 1. Example of Rhinocal resistance units used in this study. increasing resistances (decreasing diameters) to represent a wide range of human nasal resistances. The total fixed resistances of the units were approximately $0.09 \mathrm{~Pa} / \mathrm{cm}^{3} / \mathrm{s}(\mathrm{R} 1), 0.27 \mathrm{~Pa} /$ $\mathrm{cm}^{3} / \mathrm{s}$ (R2), $0.55 \mathrm{~Pa} / \mathrm{cm}^{3} / \mathrm{s}$ (R3) and $0.63 \mathrm{~Pa} / \mathrm{cm}^{3} / \mathrm{s}$ (R4) at P150 using the classic method.

\section{Measurement of NAR}

The rhinomanometer was calibrated at the beginning of each study day using a rotameter (or flow meter) for calibration of airflow and a slopping paraffin manometer for calibration of pressure. Measurements of NAR were taken using active rhinomanometry where airflow was provided by normal quiet inhalation and exhalation from the mouth through the Rhinocal resistance units to mimic human respiration in a normal rhinomanometry study.

For each Rhinocal resistance units, NAR was measured using the classic and 4-phase rhinomanometry method (at P75 and P150). For each measurement of NAR, four consecutive sets of four respiratory cycles were obtained and the coefficient of variation (CV) was calculated. In our daily usage of rhinomanometry, a CV of less than $10 \%$ for repeated measurements is used to validate the measurements.

The flow heads were calibrated using the rotameter at the end of each series of measurements with each Rhinocal resistance unit. All the results from a series were to be discarded if there were any discrepencies in airflow calibration between the start and finish of use of each Rhinocal unit, which may be the result of condensation or accumulation of moisture in the flowhead from the expired air.

All measurements and calibration of the rhinomanometer were standardised according to the study site Standard Operating Procedures (SOP) in a quiet laboratory room at room temperature of $25 \pm 1^{\circ} \mathrm{C}$.

\section{Results analysis and statistics}

The Statistical Package for the Social Sciences version 20 (IBM SPSS Statistics 20) and the Microsoft Excel 2011 version 14.1.2 for the Macintosh platform was utilised for statistical analysis.

Data of nasal resistance $\left(\mathrm{Pa} / \mathrm{cm}^{3} / \mathrm{s}\right)$ at $\mathrm{P} 150$ and $\mathrm{P} 75$ for both methods were expressed as the means \pm S.D. The correlation between the results obtained from both methods were analysed with Mann-Whitney $\mathrm{U}$ test $(\mathrm{HO}=$ no significant difference between the two methods) and the strength of correlations was tested with Spearman rank method. A value of $p<0.05$ was considered significant. The extent of agreement between both methods was also investigated using the Bland-Altman method with limits of agreement $( \pm 2 S D)$. 


\section{Results}

Flowhead calibration

There were no discrepancies in airflow calibration found between the start and finish of usage of each Rhinocal resistance unit. Therefore, no measurement series were discarded.

\section{Coefficient of variation (CV)}

The CV value for all the four consecutive measurements for each method and resistance unit was less than $10 \%$ (mean of $1.15 \%$, range from $0-3.54 \%$ ), therefore, no measurements needed to be repeated.

\section{Comparison of both methods}

The results were divided into measurements taken at P75 and P150 as well as inspiratory and expiratory measurements. Figures 2 and 3 illustrate the comparison of NAR values obtained using both the classic and 4-phase rhinomanometry method in each category, along with their standard deviations.

Mann-Whitney $U$ test showed no statistically significant difference for all the values compared ( $U>U_{\text {critical }}$ for sample size, $p>0.05$ ) (Table 1). The null hypothesis was therefore accepted that there are no statistically significant differences between the results obtained using the two different mathematical models at P150 and P75.

A Spearman's Rank Order correlation was also run to determine the relationship between the nasal resistance values obtained using the classic and 4-phase rhinomanometry. There was a strong, positive correlation between the results measured using both methods at P150 and P75, which was statistically significant (Spearman's correlation coefficient, $r_{s}=1.000, p<0.001$ for all comparisons).

Figure 4 shows a scatter plot of NAR measurements using Classic method at $150 \mathrm{~Pa}$ against NAR measurements using 4-phase rhinomanometry method at $150 \mathrm{~Pa}$ across all four model noses. It demonstrates a very close agreement between values obtained from both methods on the line of equality. Similar appearance was also found on the scatter plot of measurements performed at $75 \mathrm{~Pa}$.

The Altman-Bland plots for all the model noses at both $150 \mathrm{~Pa}$ and $75 \mathrm{~Pa}$ have scatter points within the limit of agreements of \pm 2 SD, which suggest good agreement between both methods. The intervals for limits of agreement were so small (range of \pm 2SD was 0.001-0.02 Pa/cm ${ }^{3}$ for $150 \mathrm{~Pa}$ and $0.002-0.03 \mathrm{~Pa} / \mathrm{cm}^{3}$ for $75 \mathrm{~Pa}$ ) that we are confident that it would not be clinically significant, allowing both methods to be used interchangeably.

Figure 5 shows one example of the Altman-Bland plot for model
Table 1. Results of Mann-Whitney $U$ test comparing values obtained using both methods across different resistances.

\begin{tabular}{|c|c|c|c|c|}
\hline & \multicolumn{4}{|c|}{ Mean rank } \\
\hline & $\mathbf{U}$ & Classic & PR & $\mathbf{p}$ \\
\hline P75 Inspiration & 8.0 & 4.50 & 4.50 & 1.00 \\
\hline P75 Expiration & 6.5 & 4.13 & 4.88 & 0.77 \\
\hline P150 Inspiration & 7.5 & 4.63 & 4.38 & 0.97 \\
\hline P150 Expiration & 6.5 & 4.13 & 4.88 & 0.77 \\
\hline
\end{tabular}

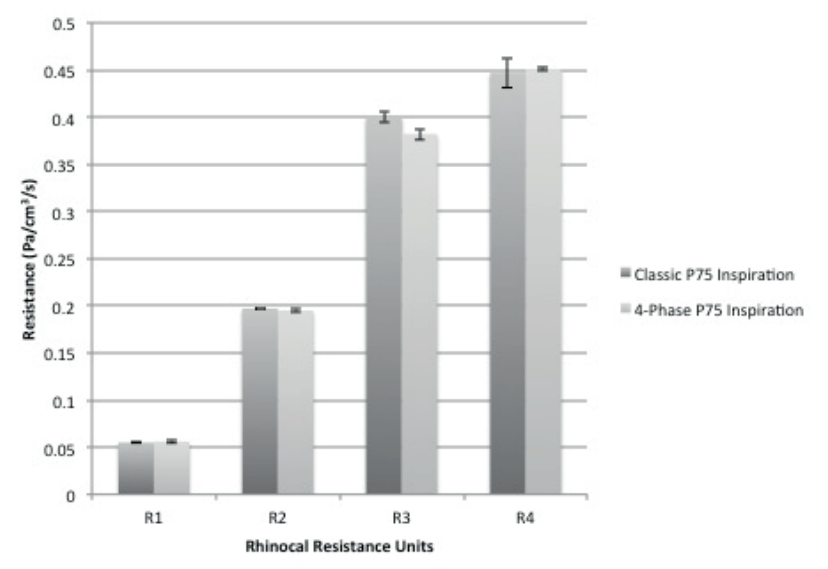

Figure 2. Rhinomanometry readings from both methods at P75 Inspiration. Error bars ( \pm 2 standard deviations) are shown.

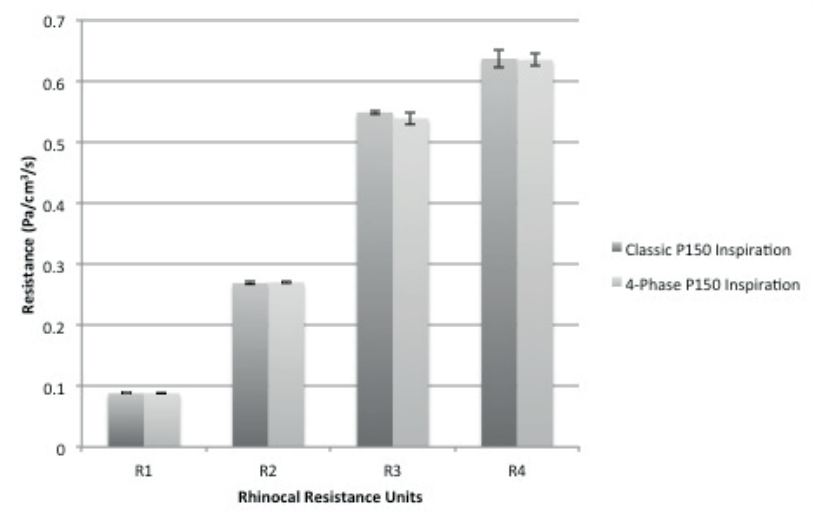

Figure 3. Rhinomanometry readings from both methods at P150 Inspiration. Error bars ( \pm 2 standard deviations) are shown.

nose R4 (highest resistance) at 150 Pa where the difference between NAR measurements of both methods was plotted against the mean NAR values of both methods.

\section{Discussion}

In 2010, Vogt et al. ${ }^{(7)}$ introduced a new method of calculating nasal resistance called 4-phase rhinomanometry (4PR) where 


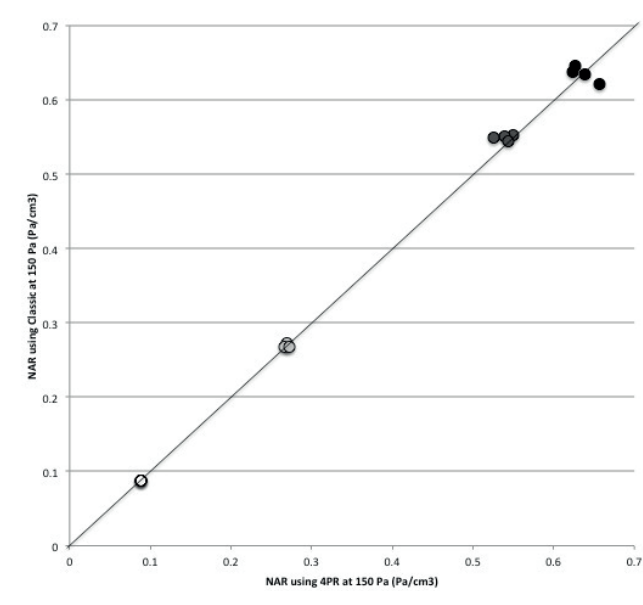

Figure 4. Scatter plot showing close agreements between NAR measured using both methods at $150 \mathrm{~Pa}$ on the line of equality.

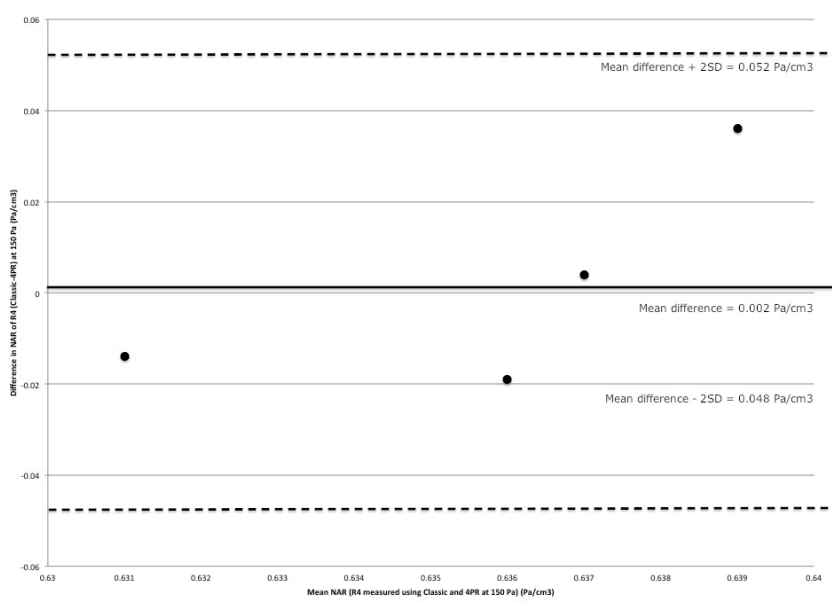

Figure 5. An example of Altman-Bland plot for NAR measurements of model nose $\mathrm{R} 4$ at $150 \mathrm{~Pa}$. emphasis was placed on analysis of the nasal breathing cycle in four different phases and included a factor of time as one of the key parameters as well as intranasal pressure and flow.

Vogt et al. ${ }^{(7)}$ described the necessity to carry out 4-phase rhinomanometry according to the recommendations of the ISOANA in the "Consensus report on acoustic rhinometry and rhinomanometry" (5), which states that "for 4-phase rhinomanometry, resistance is determined for phase 1 (ascending inspiratory phase) and phase 4 (descending expiratory phase) of the four loop rhinomanometry by using the "highest possible flow" at the pressure of $150 \mathrm{~Pa}^{\prime \prime}$. The ascending inspiratory and descending expiratory curve parts were chosen because they are much more consistent and reproducible ${ }^{(5)}$.

Two additional new parameters were also introduced in 4-phase rhinomanometry:

1. Vertex resistance (VR), which is the resistance at the point of maximum flow during inspiration or expiration in a normal breath ${ }^{(7)}$.

2. Effective resistance $\left(R_{\text {eff }}\right)$, which is equivalent to the average of all the resistances during either inspiratory, expiratory or the entire breath ${ }^{(12)}$.

Many advantages of 4-phase rhinomanometry over other methods have been claimed and include:

1. Better diagnostic information due to representation of the entire work of breathing rather than measuring resistance at only one point ${ }^{(7)}$.

2. Better correlation of the logarithmic transformation of the resistance values (LVR and LER) with subjective feeling of obstruction on the visual analogue scale (VAS) ${ }^{(12)}$.

3. Better functional diagnosis and surgical planning as it takes into account the 'valve problems' and physiological Bernoulli's effects in breathing ${ }^{(12)}$.

4. Increased sensitivity and specificity of rhinomanometry by allowing practical classification of severity of all degrees of nasal obstruction without losing any data in subjects where $150 \mathrm{~Pa}$ cannot be reached ${ }^{(12)}$.

However, the validity of 4-phase rhinomanometry has recently been questioned by Clement et al. ${ }^{(13)}$ who state that the loops and hysteresis analysed by this method are an artifact of the equipment rather than caused by pathological nasal conditions and that this reduces considerably the clinical value of 4-phase rhinomanometry.

Modern computerised rhinomanometers have the capabilities to measure NAR using various mathematical models, and the clinicians and researchers may be confused by the choices available between the classical, Broms and 4-phase rhinomanometry.

A literature search using PubMed on 13 March 2014, employing the search term "Rhinomanometry" yielded 303 results within the last 5 years. Of these, information was retrieved regarding the rhinomanometry method and instrument used in 74 papers where 62 (83.8\%) of the studies used the classic method, 7 (9.4\%) used Broms, 4 (5.4\%) used 4-phase rhinomanometry and 1 (1.4\%) used combination of different methods. Table 2 illustrates a summary of some of the commonly used methods and rhinomanometers by the authors in these papers.

Vogt et al. ${ }^{(7)}$ have described the differences in data acquisition and method of data averaging between the classic and 4-phase rhinomanometry methods. In the classic method, alternating va- 
Table 2. Summary of the methods and rhinomanometers used in various studies over the last 5 years. This information does not represent the product's ability to measure nasal resistance using other methods.

\begin{tabular}{|c|c|c|c|c|c|c|}
\hline \multirow{2}{*}{ Company } & \multirow{2}{*}{ Country } & \multirow{2}{*}{ Name of model } & \multicolumn{4}{|c|}{ Methods used in study } \\
\hline & & & Classic & Broms & 4PR & Combination \\
\hline Atmos Medical & Germany & Atmos 300 Rhinomanometer & 13 & & & \\
\hline GM Instruments & UK & NR6 Clinical/Research & 6 & 4 & & 1 (Classic and Broms) \\
\hline RhinoMetrics & Denmark & $\begin{array}{l}\text { SRE2000/2100/ } \\
\text { Rhinostream }\end{array}$ & 9 & 1 & & \\
\hline Sibelmed Group & Spain & RHINOSPIR-PRO & 7 & & & \\
\hline RhinoLab & Germany & HRR2 & 2 & & 4 & \\
\hline Nihon Kohden Co & Japan & Rhinorheograph MRP-3100 & 6 & & & \\
\hline $\begin{array}{l}\text { Allergopharma Joachim } \\
\text { Ganzer KG }\end{array}$ & Germany & Rhinotest MP500 & 4 & & & \\
\hline Homoth & Germany & Rhino 4000 & 3 & & & \\
\hline Medtronic & Italy & Rhinomanometer SR2000 & 3 & & & \\
\hline IBBAB & Sweden & Rhino-Comp & & 2 & & \\
\hline Menfis Biomedica & Italy & Rynozig/Rhino-Kit & 2 & & & \\
\hline ZAN 100 & Germany & ZAN Messgeraete & 2 & & & \\
\hline EVG GmBH & Germany & Rhinotest 2000 plus & 1 & & & \\
\hline Euroclinic & Italy & RhinoPocket & 1 & & & \\
\hline Pistone Instruments & Hungary & Pistone Rhinomanometer & 1 & & & \\
\hline MircroTronics Corp & USA & $\begin{array}{l}\text { PERCI-SAR System } \\
\text { rhinomanometer }\end{array}$ & 1 & & & \\
\hline Rhinosoft & Germany & Hortmann & 1 & & & \\
\hline
\end{tabular}

lues for flow and pressure are sequentially collected and placed in a xy-Cartesian system where a regression line that starts at the origin of the axis is constructed ${ }^{(7)}$. On the other hand, in 4-phase rhinomanometry, the flow and pressure data uptake are separately and visually controlled, and used to construct a "representative breath" as a real-time procedure ${ }^{(7)}$. This data is then transferred into the Cartesian system to generate an open loop (with greater opening at the inspiratory side) that does not run through the intersection of the flow and pressure axes ${ }^{(7)}$.

The NR6 Rhinomanometer (GM Instruments, Glasgow, UK) uses NARIS software that allows nasal resistance measurements using either classic, 4-phase rhinomanometry or Broms method. So far, there have not been any comparative studies between the simple classic and more complex 4-phase rhinomanometry.
Our results show that there is no statistically significant difference between the measurements taken at P150 and P75 for both classic and 4-phase rhinomanometry when using four different fixed resistances. There were also strong, positive correlations between values obtained with both methods, which are statistically significant. The comparison of the results obtained by both the classic and 4-phase methods show a linear relationship across the range of resistances used in this study as illustrated in Figure 4, and only at the higher resistances is there any slight spread of the results, which is to be expected as the airflow becomes more turbulent at the higher resistances ${ }^{(14,15)}$.

In general the results clearly demonstrate that the simple classic and the more complex 4-phase rhinomanometry give the same values for resistance when measured across a wide range of resistances. Therefore, all the additional advantages claimed by Vogt et al. ${ }^{(7)}$ become irrelevant. We have also not found any dif- 
ferences regarding the respiratory force required to achieve 150 $\mathrm{Pa}$ in both methods and have managed to achieve those pressures with normal quiet breathing across the different Rhinocal units.

One criticism that could be directed against this research is that simple model noses were used rather than human volunteers, but in fact the results are probably more reliable when using model rather than real noses. The human nose is not a simple tube! But the principle of measuring resistance with a rhinomanometer is the same for a simple tube model nose and a complex nasal airway. If the flow through each and the pressure drop across each is the same then each will have the same resistance value. A rhinomanometer only measures the flow and the pressure drop, and therefore it is quite acceptable to use a model nose to calibrate a rhinomanometer and this is the method of calibration recommended by the 2005 Consensus report on rhinomanometry ${ }^{(5)}$. If a complex nasal structure has a pressure drop of $75 \mathrm{~Pa}$ and a flow of $100 \mathrm{~cm}^{3} / \mathrm{sec}$ then its resistance will be measured as $0.75 \mathrm{~Pa} \mathrm{~cm} / 3 \mathrm{sec}$. Similarly if a model nose has a pressure drop of $75 \mathrm{~Pa}$ and a flow of $100 \mathrm{~cm}^{3} /$ $\mathrm{sec}$ the rhinomanometer will measure the resistance as $0.75 \mathrm{~Pa}$ $\mathrm{cm}^{3} / \mathrm{sec}$. The various clinical conditions that may affect the nose are irrelevant when considering measurement of resistance with a rhinomanometer. When comparing methods of calculating resistance on a rhinomanometer, it is better to use a standardized model resistance with a stable fixed resistance as in the present study, rather than a real nose with an unstable resistance. The real nose will introduce uncontrolled variability of resistance into the measurements whereas the model nose will provide a stable resistance.

There is also the fact that these model noses were first developed in $1997^{(11)}$ and have been used for over 16 years as standard calibrating devices for rhinomanometers.

From this study, we can conclude that there is a high degree of conformity between resistances measured by the classic and 4-phase rhinomanometry methods. If we apply the principle of "lex parsimoniae" or Ockham's razor, the simpler the method or hypothesis the better, the complexity of 4-phase rhinomanometry does not provide any benefit over the simpler classic measurements, as both methods give the same resistance values.

\section{Acknowledgements}

We would like to thank Eric Greig (GM Instruments, UK) for providing us with the Rhinocal resistance units for this study.

\section{Authorship contribution}

$R$ Eccles was involved in the original idea and design of the study and interpretation of the results. E Wong was involved in the design, conduct and analysis of the study and in writing the article.

\section{Conflicts of Interest}

None. The authors have no financial interests in any company manufacturing or marketing rhinomanometers, and this study was funded by Cardiff University.

\section{References}

1. Eccles R. A guide to practical aspects of measurement of human nasal airflow by rhinomanometry. Rhinology. 2011; 49: 2-10.

2. Moore M, Eccles R. Objective evidence for the efficacy of surgical management of the deviated septum as a treatment for chronic nasal obstruction: a systematic review. Clin Otolaryngol. 2011; 36: 106-113.

3. Nathan RA, Eccles R, Howarth PH, Steinsvag SK, Togias A. Objective monitoring of nasa patency and nasal physiology in rhinitis. J Allergy Clin Immunol. 2005; 115: S442-459.

4. Clement PA. Committee report on standardization of rhinomanometry. Rhinology. 1984; 22: 151-155.

5. Clement PA, Gordts F. Consensus report on acoustic rhinometry and rhinomanometry. Rhinology. 2005; 43: 169-179.

6. Broms P. Rhinomanometry thesis. Acta Otolaryngol. 1980.

7. Vogt K, Jalowayski AA, Althaus W Cao C, Han D, Hasse W, et al. 4-PhaseRhinomanometry (4PR)--basics and practice 2010. Rhinol Supp.l 2010: 1-50.
8. Eichler J, Lenz H. Comparison of different coefficients and units in rhinomanometry. Rhinology. 1985; 23: 149-157.

9. Clement P, Marien J. The use of a mathematical model in rhinomanometry. Rhinology. 1980; 18: 197-207.

10. Sipila J, Suonpaa J, Laippala P. Evaluation of nasal resistance data in active anterior rhinomanometry with special reference to clinical usefulness and test-retest analysis. Clin Otolaryngol Allied Sci. 1992; 17: 170177.

11. Sipila J, Suonpaa J. Long-term stability of rhinomanometer calibration. J Otolaryngol. 1997: 26: 49-52

12. Vogt K, Zhang L. Airway assessment by four-phase rhinomanometry in septal surgery. Curr Opin Otolaryngol Head Neck Surg. 2012; 20: 33-39.

13. Clement PA, Halewyck S, Gordts F, Michel O. Critical evaluation of different objective techniques of nasal airway assessment: a clinical review. Eur Arch Otorhinolaryngol. 2014 Jan 20. [Epub ahead of print].

14. Clement PA, Hirsch C. Rhinomanometry--a review. ORL J Otorhinolaryngol Relat Spec. 1984; 46: 173-191.

15. Schumacher MJ. Rhinomanometry. J Allergy Clin Immunol. 1989; 83: 711-718.

Prof. Ronald Eccles

Common Cold Centre and Healthcare

Clinical Trials

Cardiff School of Biosciences

Cardiff University

Cardiff CF10 3AX Wales

United Kingdom

Tel: +44-(0)292-087 4102

Fax: +44-29-2087 4093

E-mail: eccles@cardiff.ac.uk 